Methods The NRCWE has been working with the development and implementation of a relevant KTE-strategy on several levels:

a. For the entire research center

b. In the different research areas

c. In specific research projects

d. In the dissemination of research.

Results The aim is not only to increase the use of research results at the workplaces but also to strengthen the Danish Working Environment Authority, The Ministry of Employment's, the social partners and occupational health professional's use of research-based knowledge.

Conclusion Experiences and preliminary results from projects within different research areas will be presented iincluding what the new strategy means for the communication of research results.

\section{IMPROVING PUBLIC CORPORATE REPORTING ON OCCUPATIONAL HEALTH}

Bastian Buck*. GRI, Amsterdam, The Netherlands

\subsection{6/oemed-2018-ICOHabstracts. 194}

Aim of special session Thousands of companies globally report publicly on their occupational health programs and impacts. This information is used by a variety of stakeholders, such as investors, to inform decision making about companies. The availability of this information is, however, not yet widespread, and there are challenges with the quality and comparability of the data. A number of efforts are underway to improve and standardise this information. This session offers to learn from key organisations and experts in the field about latest developments on what is expected from companies regarding occupational health measurements and public disclosure. This session will also unveil the updates to the GRI Occupational Health and Safety reporting standard, which will outline minimum transparency expectations for companies globally around occupational health - including basic data on work-related illnesses, the management of health hazards, and the use of occupational health services and worker health promotion programs.

${ }^{1}$ Ms. Nancy J. Leppink, ${ }^{2}$ Ms. Laura Espinach, ${ }^{3}$ Mr. William G. Perry, ${ }^{4}$ Dr. Herbert J. Schilthuis

${ }^{1}$ International Labour Organisation, Geneva, Switzerland

${ }^{2}$ GRI, Amsterdam, The Netherlands

${ }^{3}$ U.S. Occupational Safety and Health Administration, Washington, DC, USA

${ }^{4}$ Heineken International, Amsterdam, The Netherlands

\section{4a THE NEED FOR RELIABLE DATA AND ROBUST INDICATORS TO DRIVE IMPROVEMENTS IN OSH PERFORMANCE}

NJ Leppink. International Labour Organisation, Geneva, Switzerland

10.1136/oemed-2018-ICOHabstracts. 195

International Labour standards promulgated by the International Labour Organisation have long called for ILO constituents to establish and support notification and recording systems for the collection of reliable data on work-related fatalities, injuries and diseases. The ILO has developed guidance and set out good practices in response to well document challenges constituents face when working to establishing effective notification and recording systems. These challenges are both technical and behavioural in nature. The United Nations Sustainable Development Goals, which require countries to report the frequency rates of fatal and non-fatal occupational injuries, by sex and migrant status has put the spotlight on the reliability of the data countries are reporting and the need for countries to improve notification and reporting systems before that indicator is a true measure of $\mathrm{OSH}$ performance. For this indicator to be relevant it should be accompanied by a means for measuring the capacity of countries' notification system to collect reliable and comparable data. Frequency rates of fatal and non-fatal injuries are lagging indicators and should be coupled with leading indicators that drive behaviours that correlate with improvements in $\mathrm{OSH}$ performance. Leading indicators need to be supported by research and have applicability to variety of contexts and the future of work. Leading indicators can be more readily aligned with positive incentives, such as improved productivity and competitiveness. Leading indicators may also be more effective in addressing occupational disease. Leading indicators need to be developed through a collaborative and consultative process engaging representatives of governments, employers, workers and the public to ensure their viability and acceptance.

\section{4b NEW STANDARD ON OCCUPATIONAL HEALTH AND SAFETY REPORTING}

L Espinach. GRI, Amsterdam, The Netherlands

10.1136/oemed-2018-ICOHabstracts.196

The GRI Sustainability Reporting Standards are used by more than 4000 organisations in over 90 countries to report on their economic, environmental and social impacts - including occupational health and safety (OHS) impacts. The GRI Standards are referenced in policy and regulation in more than 50 countries, and by nearly 40 stock exchanges worldwide. They are issued by the Global Sustainability Standards Board (GSSB), GRI's independent standard-setting body, and developed following a thorough Due Process Protocol, which ensures a transparent process and provides many opportunities for input from diverse stakeholders. GRI is reviewing its OHS reporting standard to align it with internationally-agreed best practice and recent developments in OHS management and reporting practice. The project addresses important topics such as the reporting of occupational illnesses, occupational health services, and worker health promotion, and will include a combination of leading and lagging indicators, as well as management approach disclosures. A multi-stakeholder expert Working Group is revising the content, and includes leading experts from the ILO, the Centre for Safety and Health Sustainability, IOSH, U.S. OSHA, as well as leading multinationals, among many others. This process will deliver a set of best practice metrics for organisations around the world to report on their OSH impacts in a standardised way. Ultimately, the transparency created by such a standard is intended to lead to positive change, thus contributing to sustainable development. The final standard is expected to be published during Q2 2018, the details of which will be unveiled at ICOH 2018. 